man, aged 20 years. There was a troublesome puncture and bleeding; blood coming with cerebro-spinal fluid. The patient got analgesia up to one inch above the pubes, but as it was an appendix operation a general anæsthetic had to be given. Case 39 , a man, aged 25 years, with varicocele; there was an easy puncture and only a partial analgesia was obtained. The skin incision caused some pain and a general anæsthetic was necessary. Case 43, a man, aged 57 years. There was a troublesome puncture, blood coming with cerebro-spinal fluid. Absolutely no effect was produced. McGavin ${ }^{6}$ has also recorded three very similar cases where little or no effect was produced.

Three explanations of these failures have been offered: (1) inactive stovaine; (2) a failure to land the full dose within the spinal theca; and (3) insusceptibility of the patient. I feel convinced that the cause in cases such as the above is the fact that the compound has not been wholly landed within the dural sac, but has really been injected outside. It is possible for this accident to occur even though cerebro-spinal fluid has been got. By using Barker's fine cannula it is hardly possible for the injection to escape between the needle and the post layer of the dural sac unless the patient moves at the time of injection when the point might slip out. With a very lax sac, however, it is quite easy to puncture both layers of the sac and when injection is made for the whole or part of the compound to escape anteriorly. This is undoubtedly not common, but I suggest it as accounting for some of the cases where no effect has been produced. I had one other case where the injection caused absolutely no effect, and so convinced was I that the compound had not entered that I repunctured and again injected the full dose. 'I'his acted in absolutely the usual way. I was not able to give any of the three failures a second injection, but had it been done, failure might have been prevented. It is difficult to say whether the fact that blood came with the cerebro-spinal fluid and in one case continued to do so even after two drachms had been withdrawn, had anything to do with the failure. It is, of course, always a possibility that the stovaine may be inactive, but when freshly and carefully prepared this is not likely. Provided the full dose of active stovaine is injected accurately within the sac it is hardly conceivable that it should act on the nerves of one person and fail utterly to affect those of another. I feel that the explanation of idiosyncrasy is only to be accepted when all others fail. Where the analgesia cannot be got to rise it is always possible that some of the heavy compound has run down into the sacral curve and got imprisoned there. While these failures are undoubtedly flaws in the method I feel that they are all preventable and with increased skill and experience will not occur at all.

Length of anaigesia.-The longest operation performed was a frcal fistula of the croum which lasted 80 minutes. Analgesia to a needle has been noted in the legs as long as two hours after injection. Generally speaking, however, analgesia from 50 to 90 minutes can be relied on, with rather a shorter period for the epigastric region.

After-effects.-No bad results of any kind have developed afterwards which could be traced to the analgesia. Headache and sickness are occasional sequelæ but have not been marked in our series. 35 of the cases have had absolutely no headache or sickness. Five cases, mostly nervous patients, have been troubled with sickness and five have had some headache which, however, has always been controlled by aspirin or phenacetin. It is to be noted that none of the acute abdominal cases have had the least trace of headache, nausea, or sickness. The paralysis of the legs has always passed off completely in from one and a half to three hours, and no prolonged or permanent paralysis has been seen. There has never been any trace of meningeal irritation. One case was operated on twice with stovaine, and at the second operation, five days after the first, the cerebro-spinal fluid was found quite normal. Paralysis of the external rectus of the eye, which has been recorded, ${ }^{7}$ has not been seen in any of the cases. Retention of urine does not seem to be more marked after using spinal analgesia. As a matter of fact, most of the hernias and abdominal cases passed urine themselves. Tympanites has been present next day in a certain number of the cases but never to any marked extent. As many as possible of the cases have been examined a month

6 Loc. cit.
7 Torrance: Surgery, Gynæcology, and Obstetrics, December, 1907. or si
well.

Shock.-C'The question whether spinal analgesia prevents shock is one of the greatest importance and has been urged as one of its chief advantages. Dean, ${ }^{8}$ who has drawn special attention to this aspect of the subject, is of the opinion that it is the method par excellence in acute abdominal cases where shock is feared. One of our abdominal cases, an operation on the stomach and transverse colon of 80 minutes' duration, undoubtedly suffered from shock three hours later, but in her case the analgesia had passed off before the end of the operation and some chloroform was required for closing the abdominal wall. None of the other cases have shown any signs of shock and everyone has been struck with how satisfactory the method is in weakly patients and in acute abdominal conditions. It is also striking that such procedures as dilatation of the sphincter, ligature and division of the cord, division of the foreskin and division of the peritoneum not only give rise to no pain but do not affect the pulse in the slightest degree.

Conclusions. - In ordinary healthy people it comes to be a matter of choice whether spinal analgesia is used or not. Those who have a dread of general anasthesia will, as a rule, choose spinal analgesia, and there now seems no reason why they should not have the benefit of it. Nervous patients, on the other hand, will usually prefer general anæsthesia. It is, however, when an operation has to be performed on a patient unsuited for general anæesthesia that the great advantage of the method is seen. When properly used it has no bad effect on the heart or lungs, and is therefore much safer in some cases. I have also been struck with how well suited it is for certain types of cases which are unfavourable for general anæsthesia, such as old people with arterio-sclerosis, weak, feeble patients, and those suffering from certain acute abdominal conditions. Alcoholics who are notoriously troublesome to anæesthetise do excellently well with spinal analgesia. Tuffier $^{9}$ also points out that it can often be safely used where an operation has had to be abandoned on account of anxiety with the anæsthetic and records two cases of this nature. In our own series we have had two cases (a frcal fistula and a hæmorrhoid case) where the patients took the anæsthetic so badly that it was discontinued. They were both operated on next day under stovaine without any anxiety.

From a study of the recorded cases and from my own experience of this method I feel that it can now compare favourably in point of safety with general anxsthesia. Moreover, I think there is little doubt that in a fair number of surgical conditions it is the safer and better method and its use gives the patient an increased chance of recovery. At the same time it must be clearly understood that a careful study of the subject and the utmost care in carrying it out are necessary to insure its success and safety. Dr. J. Crawford Renton has operated on the majority of the cases and has been much pleased both with the analgesia and with the condition of the patients after operation. I am indebted to him for opportunities of carrying out this method. I would also like to thank his house surgeons, Dr. T. P. Grant and Dr. H. M. Grainger, for their assistance. Glasgow.

\section{AN APPLICATION OF OPSONIC METHODS IN COMPARING HUMAN AND BOVINE TUBERCULOSIS.}

\section{By F. L. POChIN, M.D., C.M. Edin., D.P.H. СаMв.}

UNTIL 1901 it was generally thought that tuberculosis in animals and man was one and the same disease. In that year, however, Koch created a sensation among those assembled at the British Congress on.Tuberculosis by stating that, in his opinion, human tuberculosis differed from bovine and cannot be transmitted to cattle. Further, he maintained that bovine tuberculosis is scarcely, if at all, transmissible to man. ${ }^{1}$ His opinion, it will be remembered, was arrived at as the result of the following experiments. 1. Six bovines were fed for seven months with food mixed with sputum 
containing tubercle bacilli of human origin. None of them contracted the disease. 2. The same result was obtained with four animals which were caused to inhale the bacilli in the form of spray. Injection of bacilli into the peritoneal cavity or subcutaneously was no more successful. 3 . Swine, asses, sheep, and goats were also unaffected. 4. In all cases where bacilli of bovine origin were substituted, the other conditions remaining the same, infection followed. ${ }^{2}$ Koch then pointed out that experiments with human beings to determine their relative susceptibility were obviously impossible, but, in the opinion of the speaker, infection of the human subject was very uncommon; and he emphasised the last point on the ground that primary tuberculosis of the intestine is very rare, whereas it ought to be one of the commonest of diseases if the danger of infection through milk is real, owing to the quantity of milk consumed by children.

These opinions of Koch were contested at the Congress. They were contrary to the finding of two Royal Commissions which had been held in this country shortly before, and the general consensus of opinion was against Koch. Woodhead, ${ }^{3}$ Cohnheim, Aufrecht, and Peterson, ${ }^{4}$ all held that primary tuberculosis in man is comparatively common. This opinion was shared by the large majority of authorities in this country, and the evidence in favour of infection being due to tuberculous milk and meat was very strong. ${ }^{5}$ Ravenel described striking cases in support of this view. ${ }^{6}$ Hueppe quoted further cases to the same effect. ${ }^{7}$ Crookshank combated the idea that human tuberculosis cannot be transmitted to bovines by describing successful inoculations carried out by himself and Sidney Martin. ${ }^{8}$ It was, however, felt that opinions expressed so emphatically by an authority of Koch's eminence on a matter so nearly affecting the public health demanded the fullest investigation, and a Royal Commission was appointed to determine the questions at issue, whose findings were antagonistic to Koch's opinions, he having been misled, in the opinion of the Commission, by using only one strain of the bacillus and that not a very virulent one.

Koch, as I have said, in his speech in 1901 stated that experiments on the human subject to determine the effects of the bovine bacillus were out of the question, and this was obviously true when he made the statement, but in thinking over the whole matter it occurred to me that since that time the researches of Wright and Douglas on the opsonic effects of the blood fluids and their methods of estimating the opsonic index had placed in our hands an exact method, not only of experimenting with and ascertaining the resistance of human beings to the two strains of bacilli, but of extending the experiments to bovines and measuring their resistance also. It appears evident that a method of investigation which does not involve inoculation and feeding experiments or the infection and destruction of the animal will be advantageons on the ground of cheapness and expedition, and might be more certain and conclusive. If also it enables investigations to be carried on with the human subject with equal ease and certainty it will be still more valuable, a further advantage being the possibility of a very much larger series of observations. With this object in view I have carried out a series of illustrative experiments, with the results detailed in the succeeding part of this article.

The technique adopted was that of Wright and Douglas, with certain necessary modifications. Emulsions of human and bovine tubercle bacilli respectively were obtained from the Lister Institnte, and every effort was made to get them as nearly as possible of the same strength, the origin of the two strains being guaranteed by the Institute. The same emulsions were used throughout all the observations, being stored in tubes, well shaken before use, and thoroughly centrifuged at the same time and in the same machine to get rid of clumps. Two volumes of white blood corpuscles, one of emulsion and one of serum, were used in all cases, and the time of incubation was a quarter of an hour. The strength of the emulsions had been so arranged as to give an average count of about one bacillus to each polymorphonuclear leucocyte. In the case of the bovine series the

$$
2 \text { Ibid. }
$$

3 Medical Press and Circular, 1888, p. 265.

4 Wirzburg Therapeutische Monatshefte, 1891, p. 18

5laden: The LANCET, August 10th, 1901, p. 369.

b THE LANCET, vol. ii., 1901, pp. 349, 443

7 The Lancer, August 31st, 1901, pp. 611 et seq 8 The Lancer, Nov. 2nd, 1901, p. 1177. ncubator was set to the normal temperature of the bovineviz., $38 \cdot 3^{\circ} \mathrm{C}$. In all other cases the incubator of course worked at $37^{\circ} \mathrm{C}$. The blood and leucocytes for the bovine series were obtained at the time of slaughter of the animal for food and in every case the carcass was afterwards inspected to make sure it was free from tuberculous infection. In every case the average of 100 counts was taken in arriving at the figures stated.

Bovine series. - This series comprises the result of observations taken with ten bovines of both sexes, but not differing very widely as to age, all being young adults of the age usually selected for slanghter-viz., from two to three years. The object of the observations was to ascertain whether the action of the opsonins in bovine blood was the same with regard to tubercle bacilli of both human and bovine strains, or whether there was any marked difference, which would indicate a distinction between the bacilli with regard to their susceptibility to the action of opsonins, and therefore a difference in the resistance of the animal to infection by bacilli of the different strains. The results are presented in the following table :-

TABLE I. - Number of Bacilli of Human and Bovine Origin Respectively, taken up by Polymorphonuclear Leucooytes of Cattle (Average of 100 Counts).

\begin{tabular}{|c|c|c|}
\hline Number. & Human bacilli. & Bovine bacilli. \\
\hline 1 & $4 \cdot 25$ & $2 \cdot 64$ \\
\hline 2 & $1 \cdot 00$ & 0.44 \\
\hline 3 & 1.98 & 1.06 \\
\hline 4 & 0.64 & 1.04 \\
\hline 5 & $2 \cdot 44$ & 1.85 \\
\hline 6 & $1 \cdot 85$ & 0.95 \\
\hline 7 & $3 \cdot 80$ & 0.95 \\
\hline 8 & $1 \cdot 83$ & 1.02 \\
\hline 9 & $1 \cdot 50$ & 0.65 \\
\hline 10 & $1 \cdot 40$ & 0.55 \\
\hline $\begin{array}{llll}\text { Total } & \ldots & \ldots & \ldots\end{array}$ & $20 \cdot 69$ & $11 \cdot 15$ \\
\hline $\left.\begin{array}{ccc}\text { Average } & 1000 \\
\text { counts } & \ldots & \ldots\end{array}\right\}$ & $2 \cdot 069$ & $1 \cdot 115$ \\
\hline
\end{tabular}

This table indicates that there is a marked difference in the number of bacilli of the two different strains taken up by bovine polymorphonuclear leucocytes, and therefore also in the resistance of the animal to each. It will be seen that in every case save one (No. 4) the number of human bacilli ingested by the leucocytes is considerably greater than the number of bovine bacilli so absorbed. The phagocytes in some instances absorbed about three times as many of the one strain as they did of the other, and on the grand average of 1000 counts about 85 per cent. more human bacilli were absorbed than was the case with the bovine variety. This explains the comparative immunity of the bovine to infection of human origin observed by others, and may also explain Koch's failure to infect his animals, for an animal might easily be immune to a culture of mild human virus and subsequently succumb to a bovine culture owing to its inferior resistance to the latter variety. This comparative immunity is not, however, so great as to justify the conclusion that bovines are exceptionally resistant to infection of human origin, and indeed would easily break down under the invasion of human bacilli of high virulence, as was found to be the case by the Royal Commissioners.

Resistance of children.-A series of counts was then made to ascertain the resistance of children to the bacilli of the two different strains, and a result quite the converse of that in Table I. was obtained, the experiments all giving consistent readings.

It will be seen from Table II. that the counts were much greater with the bovine bacillus than those given with bacilli of human orgin. The average figures for these ten children and for 1000 counts in each series show a greater resistance to the bovine type by 254 per cent. as compared with the resistance to human bacilli. If these observations are correct, therefore, the average country child would be about two and a half times more jikely to succumb to human infection than he would to infection through milk, assuming 
that in each case the mode of entrance to the body were the same ; and I think one might go further and omit this last proviso, for by the method under description the actual

TABLE .II.-Bacilli Ingested by Polymorphonuclear Leuoocytes of Children under Ten Years of Age.

\begin{tabular}{|c|c|c|c|}
\hline Number. & $\begin{array}{c}\text { Human } \\
\text { bacilli. }\end{array}$ & $\begin{array}{l}\text { Bovine } \\
\text { bacilli. }\end{array}$ & Remarks. \\
\hline 1 & 1.25 & $4 \cdot 04$ & Strong healthy boy. \\
\hline 2 & 0.91 & $2 \cdot 02$ & Delicate rickety boy. \\
\hline 3 & $1 \cdot 28$ & $2 \cdot 25$ & Robust boy. \\
\hline 4 & $1 \cdot 10$ & $1 \cdot 66$ & Robust girl. \\
\hline 5 & 1.06 & $1 \cdot 56$ & Healthy girl. \\
\hline 6 & 0.39 & 1.62 & Badly nourished girl. \\
\hline 7 & 0.76 & $1 \cdot 75$ & Healthy girl. \\
\hline 8 & 0.80 & 3.79 & , \\
\hline 9 & 0.74 & 2.08 & Healthy girl, phthisical mother. \\
\hline 10 & 0.58 & 1.85 & Healthy girl. \\
\hline Total ... ... & 8.89 & $22 \cdot 62$ & - \\
\hline $\left.\begin{array}{l}\text { Average of } \\
1000 \text { counts }\end{array}\right\}$ & 0.889 & $2 \cdot 262$ & - \\
\hline
\end{tabular}

resisting power of the blood, as conferred by the potency of its opsonins, is measured, and, as far as we know, this is the same in the other parts of the body as it is in the intestinal walls.

Unfortunately for the race, the degree of immunity against tuberculosis enjoyed by human beings is not great. Indeed, judging by the incidence of the disease per unit of population, it appears to be small-so small that an increase of two and a half times enjoyed in relation to the bovine variety by no means secures such a degree of safety as to warrant for one moment any relaxation of measures of precaution against infection through milk.

TABLE III.-Bacilli Ingested by Polymorphonuclear Leucooytes of Healthy Adults (Average of 100 Counts).

\begin{tabular}{|c|c|c|}
\hline Number. & Human bacilli. & Bovine bacilli. \\
\hline 1 & 0.99 & $1 \cdot 21$ \\
\hline 2 & 0.80 & $1 \cdot 46$ \\
\hline 3 & 0.66 & $1 \cdot 00$ \\
\hline 4 & 0.99 & $2 \cdot 29$ \\
\hline 5 & 0.74 & $2 \cdot 45$ \\
\hline 6 & $1 \cdot 12$ & $1 \cdot 68$ \\
\hline 7 & 0.42 & 0.93 \\
\hline 8 & $0 \cdot 84$ & $3 \cdot 90$ \\
\hline 9 & $1 \cdot 31$ & $4 \cdot 28$ \\
\hline 10 & $0 \cdot 76$ & $2 \cdot 92$ \\
\hline $\begin{array}{llll}\text { Total } & \ldots & \ldots & \ldots\end{array}$ & $8 \cdot 63$ & $22 \cdot 12$ \\
\hline $\left.\begin{array}{ccc}\text { Average } & 1000 \\
\text { counts } & \ldots & \ldots\end{array}\right\}$ & 0.863 & $2 \cdot 212$ \\
\hline
\end{tabular}

While showing some rather wide variations in individuals the above table approximates in its totals and averages very closely to the results shown by Table II. and the same remarks apply to it.

A few observations have been made by the writer in the cases of two phthisical patients who are undergoing treatment by Koch's tuberculin T.R. regulated by opsonic methods. In each of these cases the opsonic index has always been taken with bovine as well as with human emulsion to ascertain whether the indices in each set of observations move in harmony the one with the other. So far it appears that such is not the case. The index to bovine bacilli appears to be very little affected by injection of tuberculin prepared from human bacilli. As far as the observations go, however, the use of a bovine tuberculin is followed by a marked rise in the opsonic index to bovine bacilli. The observations are so far very few and this part of the subject will be submitted to further investigation.
In an ordinary country practice the number of cases available for observation is not large and the time over which such observations will have to be spread in order to get an adequate series of cases will naturally be considerable.

I think that the series of observations described in this paper tends to confirm the conclusions of the Royal Commission and to support the view that Koch's opinion was erroneous, and I also hold that this application of the discoveries and methods of Wright and Douglas affords, a certain, expeditious, and inexpensive (though tedious) mode of carrying on observations on the resistance of animals to diseases of human origin, and further that it also affords a method of gauging the resistance of human beings to virulent diseases from which man and animals suffer in common.

Fakenham, Norfolk.

\section{EPIDEMIC INFANTILE DIARRHEA. ${ }^{1}$}

BY V. J. GLOVER, M.D. LiverP., M.B., CH.B. VICT.

$$
\text { I.-Etiology. }
$$

DURING the course of my practice in the year 1904 I was struck by the great number of cases of epidemic infantile diarrhœea that I met with. Prior to this, as a lecturer on ingiene, it had always seemed to me that our evidence as to its causation was unsatifactory-in fact, it was nil. We all knew the months when it was most prevalent and the atmospheric conditions then existent; as also that breastfed infants usually escaped attacks, but that infants, especially not breast-fed and under one year of age, were the chief victims. Almost universal has been the cry to provide sterilised milk, and in towns depôts were established to supply this commodity with the result that the disease has been less prevalent where the depôts were instituted.

From this result I formed the belief that under certain conditions milk carried the infecting agent. But then there was the disturbing factor-how do the breast-fed infants who contract epidemic summer diarrhœea, small though the percentage be, contract it? This was the stumbling block. In the year 1904 I noticed that while my own infant was sleeping in the garden, with his mouth open and full of saliva, as infants' mouths usually are, several house flies were not only on his lips but actually within the mouth. The child was subsequently attacked by a most virulent diarrhoa. This was in August. From this time I focussed my attention upon the house fly. I found that the great majority of cases of diarrhœa occurred amongst the working class. The conditions of life amongst them entail that the kitchen, which is always small, hot, and stuffy, is, besides being the cooking place of the family, also the one and only living room by day. Food is practically never off the table; the milk-jug and sugar-bowl are at all times in evidence. The kitchen and scullery consequently by their temperature and contents attract the house fly. I have been conducting observations during and since 1904 and $I$ find that "whenever there is summer diarrhoa in a house there are also house files in abundance, particularly in the working man's house." If the dwelling be a larger one, as that of a wealthier man, still in the kitchen and pantries where the food is stored there is the fly again in strong numbers.

In the earlier part of 1905 I propounded my view to Lieutenant H. Pierpoint, I.M.S. (Holt Fellow in Pathology), as to the causation of epidemic infantile diarrhœa. It was as follows: "The house fly is the carrier of the infection of infantile summer diarrhoea. It infects breast-fed infants by creeping into their mouths when they are asleep; a habit of many infants is to sleep with the mouth slightly open or lips a little apart. Such infants' mouths contain a plentiful supply of saliva mixed with milk. Infants which are not breast-fed are infected by ingesta-e.g., usually the milk, an infection-carrying fly having fallen into it." As I was too busy in general practice to devote the necessary time to bacteriological research he agreed to help me when the disease became prevalent, as it did later in the year. I provided myself with sterilised milk, taking care to do the sterilisation myself. At different periods $\mathbf{I}$ caught flies in infected houses and placed them in a tube of the sterilised 